\title{
Reasons for Reperfusion Failures in Stent-Retriever-Based Thrombectomy: Registry Analysis and Proposal of a Classification System
}

(D). Kaesmacher, (D). Gralla, (DP.J. Mosimann, (DF. Zibold, (D).R. Heldner, (DE. Piechowiak, (D). Dobrocky, (D). Arnold, (D). Fischer, and (DP. Mordasini

$\stackrel{0-1}{ }$

\begin{abstract}
BACKGROUND AND PURPOSE: In 5\%-10\% of patients with acute ischemic stroke with an intention to treat with mechanical thrombectomy, no reperfusion can be achieved (Thrombolysis in Cerebral Infarction score $=0 / 1$ ). Purpose of this analysis was a systematic assessment of underlying reasons for reperfusion failures.
\end{abstract}

MATERIALS AND METHODS: An intention-to-treat single-center cohort $(n=592)$ was re-evaluated for all patients in whom no reperfusion could be achieved $(n=63)$. Baseline characteristics of patients were compared between patients with and without reperfusion failures. After qualitative review of all cases with reperfusion failures, a classification system was proposed and relative frequencies were reported. In a second step, occurrence of delayed recanalization at 24 hours after reperfusion failure and dependency on IV-tPA were evaluated.

RESULTS: In 63/592 patients with an intention to perform stent-retriever thrombectomy, no reperfusion was achieved (TICI 0/1, 10.6\%, $95 \% \mathrm{Cl}, 8.2 \%-13.1 \%$ ). Older patients (adjusted OR per $\mathrm{yr}=1.03 ; 95 \% \mathrm{Cl}, 1.01-1.05$ ) and patients with $\mathrm{M} 2$ occlusion (adjusted OR $=3.36 ; 95 \%$ $\mathrm{Cl}, 1.82-6.21$ ) were at higher risk for reperfusion failure. In most cases, no reperfusion was a consequence of technical difficulties (56/63, $88.9 \%)$. In one-third of these cases, reperfusion failures were due to the inability to reach the target occlusion (20/63, 31.7\%), while "stent-retriever failure" occurred in $39.7 \%$ (25/63) of patients. Delayed recanalization was very rare (18.2\%), without dependence on IV-tPA pretreatment status.

CONCLUSIONS: Reasons for reperfusion failure in stent-retriever thrombectomy are heterogeneous. The failure to establish intracranial or cervical access is almost as common as stent-retriever failure after establishing intracranial access. Systematic reporting standards of reasons may help to further estimate relative frequencies and thereby guide priorities for technical development and scientific effort.

$\mathbf{T}$ he technical success of endovascular stroke therapy is one of the most important modifiable predictors of therapy benefit in patients presenting with large-vessel-occlusion acute ischemic stroke. ${ }^{1,2}$ The American Stroke Association/American Heart Association guidelines continue to support stent

Received March 22, 2018; accepted after revision June 25.

From the University Institute of Diagnostic and Interventional Neuroradiology (J.K., J.G., P.J. Mosimann, F.Z., E.P., T.D., P. Mordasini) and Department of Neurology (J.K., M.R.H., M.A., U.F.), University Hospital Bern and University of Bern, Inselspital, Bern, Switzerland.

Urs Fischer and Pasquale Mordasini shared senior authorship.

This work was supported by the Swiss Stroke Society, the Bangerter Foundation, and the Swiss Academy of Medical Sciences through the "Young Talents in Clinical Research" program.

Please address correspondence to Pasquale Mordasini, MD, MSc, University Institute of Diagnostic and Interventional Neuroradiology, University of Bern, Inselspital Bern, Freiburgstr 8, CH-3010, Switzerland; e-mail: pasquale.mordasini@insel.ch

-- Indicates open access to non-subscribers at www.ajnr.org

三 Indicates article with supplemental on-line table.

http://dx.doi.org/10.3174/ajnr.A5759 retrievers as the dominant technical platform for thrombectomy; however, this may change with the final publication of A Comparison of Direct Aspiration Versus Stent Retriever as a First Approach (COMPASS) trial. ${ }^{3-5}$ Recently published large-cohort registries of patients treated with stent retrievers have shown that contemporary endovascular interventions in acute ischemic stroke are angiographically successful in up to $80 \%-90 \%$ of cases (Thrombolysis in Cerebral Infarction 2b/3). ${ }^{6,7}$ While unsuccessful reperfusion ( $\leq$ TICI $2 \mathrm{a}$ ) often results from incomplete retrieval due to distal embolization and/or clot fragmentation (TICI 2a), in some patients, no reperfusion (TICI 0/1) can be achieved ("reperfusion failure"). Reasons for such reperfusion failures may range from difficulty establishing cervical or intracranial access to the inability to dislocate and retrieve the clot despite having reached the target location and having established intracranial access. ${ }^{8,9}$ Further conceivable explanations for failures to reestablish flow are underlying nonembolic vessel diseases (eg, vasculitis, intracranial atherosclerosis) $)^{10,11}$ or thrombi of nonthrombotic origin and extraordinary composition, such as calcified or neoplastic thrombi. ${ }^{12,13}$ 
The aim of this analysis was to provide estimates of the relative frequencies of underlying causes of reperfusion failure in patients with acute ischemic stroke who underwent angiography with an intention to perform stent-retriever-based thrombectomy.

\section{MATERIALS AND METHODS}

The prospective Bernese Stroke Registry was accessed to find all directly admitted patients with acute ischemic stroke with an intention to perform stent-retriever thrombectomy from January 2012 to July 2017 ( $n=592)$. For the classification of reasons for reperfusion failure, all patients with postinterventional final Thrombolysis in Cerebral Infarction grades 0 and 1 were included. ${ }^{14}$ Most important, patients in whom no stent retriever was deployed (eg, because of access difficulties or vessel elongation) were also analyzed. The Bernese Stroke Registry was approved by the local ethics committee (Kantonal Ethics Committee Bern, amendment access number: 231/2014).

\section{Classification of Reasons for Reperfusion Failures}

After qualitative review of all cases with reperfusion failure, the underlying reasons for TICI 0/1 were classified into the following categories by a consensus of a neuroradiologist in training (J.K., 3 years of experience) and an interventional neuroradiologist (P. Mordasini, 15 years of experience).

\section{Technical Reasons: Target Occlusion Not Reached (Category I)}

- IA: Intracranial target occlusion was not reached due to marked cervical vessel tortuosity including twisted, looped, or kinked vessels. ${ }^{15}$ The proximal cervical vessels were successfully catheterized.

- IB: Target occlusion was not reached owing to failed catheterization of proximal supra-aortic vessels. The proximal cervical vessels were not successfully catheterized owing to difficult aortic arch anatomy. ${ }^{16}$

- IC: Target occlusion was not reached owing to the inability to pass a cervical ICA occlusion (eg, unpassable tandem lesion).

\section{Technical Reasons: Target Occlusion Reached (Category II)}

- IIA: Target occlusion was reached, but the operator was unable to pass the thrombus with the microwire/microcatheter. In these cases, no stent retriever is deployed.

- IIB: Target occlusion was reached, the stent retriever was deployed, but no reperfusion occured after multiple retrievals (no clot retrieval or dislocation), thus, stent-retriever failure.

- IIC: Initial reperfusion was achieved, followed by spontaneous or iatrogenic reocclusion (eg, intracranial stenosis, intracranial dissection, or perforation with subsequent vessel sacrifice).

\section{Nontechnical Reasons: Other (Category III)}

- Presumed futility.

- Adverse non-neurologic event with the need to stop mechanical thrombectomy.

- Signs of contrast extravasation without perforation (early hemorrhagic transformation).
For all cases, categorization of reasons and the evaluation regarding the primary intention of treating with a stent-retriever-based thrombectomy were based on the following information:

- Review of the initial radiologic report with respect to a written decision and interdisciplinary consensus for stent-retriever-based thrombectomy.

- Review of materials used along with an angiographic report concerning catheter changes and a description of interventional difficulties

- Review of all preinterventional and angiographic images.

\section{Patient Characteristics}

Baseline parameters, clinical outcomes, and information on recanalization status at $24 \pm 6$-hour follow-up are provided. Follow-up recanalization status was graded using the 4-step arterial occlusive lesion score ${ }^{14}$ on postinterventional intracranial vessel imaging, if available (44/63, 13 missing because only noncontrast CT was performed, 6 missing due to early death).

\section{Endovascular Therapy}

Endovascular therapy was performed immediately after CT or MR imaging under the following conditions: 1) The diagnosis of ischemic stroke was established; 2) the NIHSS score on admission assessed by a neurologist was $\geq 4$ points, isolated aphasia or hemianopia or severe paresis of 1 hand was present, or neurologic deficits recurred; 3) CT or MR angiography showed occlusion of a large intracranial artery; 4) hemorrhage was excluded; 5) neurologic deficits correlated with the vessel occlusion; and 6) no individual clinical or premorbid conditions or laboratory findings were contraindications. When the criteria for endovascular therapy were fulfilled, digital subtraction angiography was performed via a transfemoral approach using a biplane, high-resolution angiography system (Axiom Artis zee; Siemens, Erlangen, Germany) using iopamidol (Iopamiro 300; Bracco, Milan, Italy) as a contrast agent. The choice of access and retrieval technique was left to the discretion of the neurointerventionalist, taking access anatomy and occlusion pattern into account. For anterior circulation strokes, a first-line recanalization technique consists of placing an $8 \mathrm{~F}$ or $9 \mathrm{~F}$ balloon-guiding catheter over a long exchange wire as high into the cervical ICA as possible followed by stent-retriever thrombectomy under proximal balloon occlusion and manual aspiration. In cases in which placement of a balloon-guiding catheter was deemed suboptimal (eg, low position in the cervical ICA or distal common carotid artery or highly tortuous cervical vessels) or stent-retriever thrombectomy through the balloon-guiding catheter alone was unsuccessful, a 5F or 6F intermediate catheter for concomitant distal aspiration during stent-retriever thrombectomy was used as a second-line technique. Stand-alone aspiration was only used as a third-line technique after failure of stent-retriever thrombectomy. During the study period, several different stent retriever models were used, the mainstay consisting of the Solitaire device (Covidien, Irvine, California). The decision of when to abandon the procedure and whether to administer intra-arterial thrombolysis with urokinase was left to the discretion of the neurointerventionalist. 


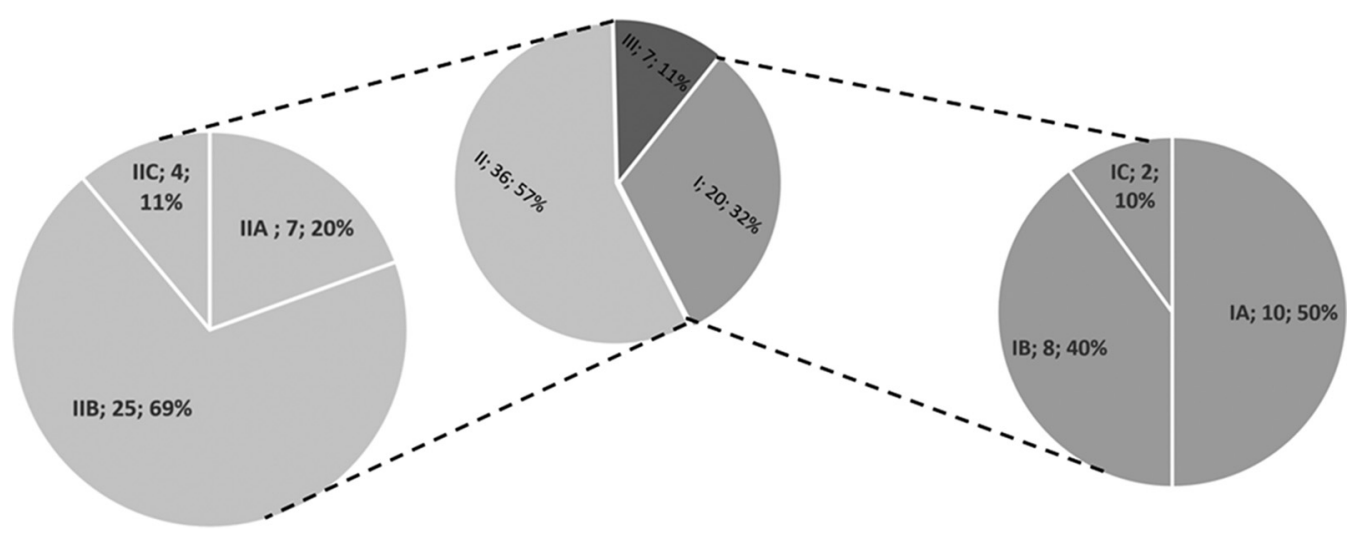

FIGURE. Distribution of reasons for reperfusion failures. Relative frequencies of reasons underlying reperfusion failures. The most common reason was reperfusion failure after intracranial access was established (category II, 36/63). Here, the most common reason was the inability to retrieve the clot despite multiple attempts, stent-retriever failure (IIB). Other reasons in this category group included the inability to pass the clot with the microwire or microcatheter (IIA) or secondary spontaneous/iatrogenic reocclusion after initial reperfusion was established (IIC). Access failures were observed in 20 cases (category I). For further exact definitions of respective subcategories, see the proposed classification scheme outlined in the "Materials and Methods" section.

\section{Statistical Analysis}

Categoric group comparisons were performed applying the Fisher exact test. Normally distributed data are presented as mean $\pm \mathrm{SD}$, while non-normally distributed data are shown as median (interquartile range). Comparison of continuous or ordinally scaled variables was performed using the Mann-Whitney $U$ test or the Welch $t$ test for independent samples (for non-normally and normally distributed variables, respectively). Estimated 95\% confidence intervals of prevalences were calculated using the normal approximation interval (Wald interval). Variables with univariate significant differences between groups were entered into a multivariate logistic regression model. Results from multivariate logistic regression analysis were presented as adjusted ORs and respective 95\% confidence intervals. Predicted probabilities were analyzed with receiver operator characteristic analysis with calculation of the area under the curve to evaluate the discriminative power of the model.

\section{RESULTS}

\section{Study Cohort}

Five hundred ninety-two patients were included (mean age, $72.2 \pm 14.3$ years; $47.3 \%$ female). Of these patients, $93.1 \%(n=$ $551)$ were treated for anterior circulation occlusions. The median symptom-onset to diagnosis interval (witnessed or last seen well) was 126 minutes (interquartile range, 90-222 minutes), and patients presented with severe neurologic deficits (median admission NIHSS, 15; interquartile range, 9-20). Other baseline characteristics are shown in the On-line Table. In 63 of 592 patients with an intention to treat with stent-retriever thrombectomy, no reperfusion was achieved (TICI 0/1, 10.6\%; 95\% CI, 8.2\%$13.1 \%)$. Patients in whom no reperfusion was achieved were older (mean age, 76.9 versus 71.6 years; $P=.004$ ), were treated later (median symptom-onset to diagnosis 155 versus 121 minutes, $P=.007)$, and had more $\mathrm{M} 2$ and posterior circulation occlusions $(P$ for overall difference $<.001)$. Other baseline characteristics did not reveal significant differences (On-line Table). When we entered significant variables derived from univariate comparison into a multivariable logistic regression model, only M2 occlusions and increased age were associated with reperfusion failure (adjusted OR $=3.36$;
95\% CI, 1.82-6.21; and 1.03; 95\% CI, 1.01-1.05, respectively, with the Nagelkerke $\left.R^{2}=0.074\right)$. The discriminative power of the multivariate logistic regression model derived from the included variables age, time to diagnosis, and M2 occlusions was weak (area under the curve $=0.665 ; 95 \%$ CI, 0.585-0.746).

\section{Distribution of Reasons for TICI 0/1}

In most cases, no reperfusion was a consequence of technical difficulties (categories I and II: 56/63, 88.9\%; 95\% CI, 81.1\%-96.6\%, Figure). One-third of reperfusion failures were due to the inability to reach the target occlusion (category I: $20 / 63,31.7 \%$; $95 \%$ CI, $20.3 \%-43.2 \%$ ). Reasons for not reaching the target occlusion were subcategorized into cervical vessel tortuosity (the proximal cervical vessel was catheterized, 10/20), failed catheterization of proximal supra-aortic vessels because of difficult acrotic arch anatomy $(8 / 20)$, or, rarely, the inability to pass a proximal ICA occlusion/stenosis in patients presenting with extracranial-intracranial tandem lesions $(2 / 20)$. If the target occlusion was reached (category II: 36/63, 57.1\%; 95\% CI, 44.9\%-69.4\%), reperfusion failure was due to the inability to pass the intracranial occlusion with the microwire/microcatheter in $7 / 36$ cases. When stent retrievers were deployed (29/36), the most common reason for failure was the inability to retrieve/dislocate the thrombus after multiple attempts (stent-retriever failure, 25/36; median attempts, 3), while in the remaining cases, iatrogenic perforation and subsequent coiling were causative (4/36). Nontechnical reasons for TICI 0/1 (category III: 7/63, 11.1\%; 95\% CI, 3.4\%-18.9\%) were an active consensus decision to stop treatment after diagnostic angiography or an initial thrombectomy attempt (presumed futility, 5/7), a non-neurologic event with the need to stop endovascular therapy (1/7), and signs of contrast extravasation without perforation, interpreted as early hemorrhagic transformation (1/7).

\section{Rescue and Patency at 24-Hour Follow-Up}

Follow-up imaging at 24 hours was available for 44/63 (69.8\%) patients without initial reperfusion. Of those patients, 8 (18.2\%) revealed substantial vessel recanalization at follow-up (arterial occlusive lesion score, $2 / 3)$, while all other patients $(36 / 44,81.8 \%)$ showed evidence of persistent occlusion without or with minimal 
recanalization (arterial occlusive lesion score, 0/1). Recanalization at follow-up tended to be observed less often if the reason for no reperfusion was a category II failure $(11.5 \%$ versus $33.3 \%, P=$ $.176)$. If intra-arterial thrombolysis was applied as a rescue, a nonsignificant trend toward higher rates of recanalization at follow-up was observed (33.3\% versus $11.5 \%, P=.125)$. No difference in 24-hour recanalization in patients with reperfusion failure was observed when comparing those treated with IV-tPA with those treated without IV-tPA $(21.4 \%$ versus $16.7 \%, P=.501)$.

\section{DISCUSSION}

The presented study suggests that reasons for reperfusion failure in patients with an intention to perform stent-retriever-based thrombectomy are not homogeneous and underline the notion that reperfusion failure in contemporary stroke thrombectomy is a multifactorial problem. ${ }^{8}$ The failure to establish intracranial or cervical access is approximately as common as the inability to retrieve the clot once adequate intracranial positioning and access to the target occlusion are established (true stent-retriever failure). The presented data highlight the need to distinguish among potential factors associated with reperfusion failure and advocate for technical development and scientific effort equally focusing on stent-retriever efficacy as well as tools and alternative access routes to improve cervical and intracranial access.

\section{Access Failures and Alternative Access Routes}

The two main domains of difficulty are the inability to reach the target occlusion and the failure to dislocate or retrieve the clot. A recent study has suggested that carotid tortuosity relates to technical failure ${ }^{17}$; however, another study did not find a significant association between carotid elongation and technical success or procedure length. ${ }^{18}$ One reason for the discrepant results of these studies may be because vessel elongation predominantly causes category I reperfusion failures, while intracranial geometry and thrombus properties may primarily relate to stent-retriever failures (category IIB). Distribution of these reasons in such cohorts may thus severely affect the sensitivity and respective power of the aforementioned analyses. Although no femoral access failure has been observed in the presented consecutive cohort, brachial ${ }^{19}$ or carotid access ${ }^{20,21}$ may serve as a reliable rescue approach in cases of femoral access failure or other category I failures (eg, in the presence of vessel tortuosity or the inability to adequately catheterize the proximal supra-aortic vessels). Until the date of this analysis, we had not used alternative access routes in a standardized fashion if the femoral artery was successfully cannulated but a category I failure had occurred. One consequence of this analysis is the institutional introduction of a more widely applied and standardized use of alternative access routes. We now consider these alternative routes not only when femoral access cannot be achieved (failed femoral artery cannulation) but also in all cases of category I failures.

\section{Retrieval Failures}

Several factors influencing stent-retriever failure have been proposed. So far, there is some preliminary evidence that MCA geometric anatomy, ${ }^{22,23}$ along with thrombus composition ${ }^{12,24-26}$ and shape, ${ }^{27}$ may predict the inability to dislocate or retrieve the clot. Other factors may include underlying vessel disease such as atherosclerosis, dissection, or vasculitis. ${ }^{10,11}$ According to current observational studies, thrombus length has not been shown to effect retrieval efficacy. ${ }^{28,29}$ Besides clot and occlusion site characteristics, stent-retriever dwelling time $e^{30}$ and respective deviceclot interaction, ${ }^{8}$ may serve as additional contributing factors. The present analysis included only patients with an intention to treat with stent-retriever-based thrombectomy. Recent randomized-controlled trial results have suggested that similar technical and clinical success rates could be achieved with aspiration techniques using large-bore catheters (COMPASS, International Stroke Conference 2018). ${ }^{31}$ A different mechanical retrieval approach is likely to increase the probability of achieving reperfusion, because some occlusions, which are refractory to one technique may respond favorably to an other approach. Currently, there is emerging evidence that the relative effectiveness of one approach over the other may depend on the localization of the occlusion (eg, anterior-versus-posterior circulation) $)^{32}$ or the shape of the proximal occlusion site. ${ }^{33}$

\section{Delayed Recanalization and Rescue Options}

While reperfusion rates in intracranial vessel occlusions after IVtPA may be as high as $60 \%$ after 7 hours, ${ }^{34}$ only a few patients had reperfusion at 24 hours after endovascular reperfusion failure, particularly after stent-retriever failure $(\sim 10 \%)$. These results provide preliminary evidence that clots not responding to mechanical treatment also show low response rates to intravenous thrombolysis and spontaneous clot lysis, corroborating findings that they may represent clots of distinct composition (eg, prominent calcification). ${ }^{12}$ In the presented cohort, rescue administration of intra-arterial thrombolytics showed a trend toward higher rates of recanalization at follow-up, without reaching statistical significance. Recently, low-dose tirofiban has been associated with increased reperfusion rates in patients treated with mechanical thrombectomy. ${ }^{35,36}$ However, the results are mainly derived from Asian cohorts, which have higher rates of underlying intracranial atherosclerosis and higher rates of early re-occlusions, thus severely limiting its transferability to other cohorts. Besides medical rescue approaches, stent placement and Y-stent-retriever maneuvers may serve as mechanical rescue approaches if an intracranial access was successfully established. ${ }^{37-39}$ A recent cohort study has suggested that the higher recanalization rates achievable with rescue permanent intracranial stent placement translated into clinical benefit without increasing the risk of symptomatic intracerebral hemorrhage. Although further studies in other populations are needed to confirm these findings, the results promote permanent stent placement as a feasible rescue technique in cases of stent-retriever failures. ${ }^{40}$

\section{Identifying Patients with a High Risk of Reperfusion Failure}

Preinterventional stratification of patients with a high chance of mechanical reperfusion failure is desirable. This is important not only because in these cases, inclusion into currently enrolling randomized-controlled trials (Multicenter Randomized Clinical Trial of Endovascular Treatment for Acute Ischemic Stroke in the Netherlands-NO IV, [ISRCTN80619088]; and Solitaire With the Intention For Thrombectomy Plus In- 
travenous t-PA versus DIRECT Solitaire Stent-Retriever Thrombectomy in Acute Anterior Circulation Stroke [SWIFT DIRECT, NCT03192332, clinicaltrials.gov]) may raise potential ethical considerations but also because primary alternative access routes might be considered beforehand. However, no reliable classification algorithm with high sensitivity and specificity is currently available. In our cohort, patients with reperfusion failure were older, treated later, and frequently had M2 occlusions. Combining those parameters, however, yielded low accuracy in correctly identifying patients with reperfusion failures. The issue of more reperfusion failures in M2 occlusions observed in the presented cohort deserves attention because a recent meta-analysis has suggested that endovascular therapy is successful in up to $85 \%$ of M2 occlusion. ${ }^{41}$ In this meta-analysis, recanalization rates were comparable between patients with M1 and M2 occlusions. ${ }^{41}$ However, the author acknowledged that the results can only be "interpreted in the context of patients with M2 occlusions that can be safely accessed by mechanical thrombectomy." ${ }^{41}$ In the present analysis, the initial intention for stent-retriever thrombectomy was crucial for inclusion, and patients were included even if no stent retriever was deployed at any time point during angiography. This criterion may differ from that in most of the retrospective studies included into the aforementioned quantitative synopsis because the major inclusion criterion was treatment with a stent retriever, rather than intention to treat with stent retrievers. ${ }^{41}$ Furthermore, the overall frequency of M2 occlusions treated with stent retrievers was small in our cohort, giving it scope for confounding due to the operator's experience and associated learning curves.

\section{Strengths and Limitations}

While the present data allow a real-world intention-to-treat analysis of the relative frequencies of reasons for reperfusion failures, there are several limitations to this study: First, category IIB is defined as reperfusion failure after multiple attempts. Thus, there may be different thresholds for different interventionalists and centers to stop at different time points, and aggressiveness of rescue approaches vary. Second, futility criteria based on a consensus between the treating neurologists and neuroradiologists may change with time (eg, advanced time windows of $>10$ hours may no longer serve as a futility reason in the era of published Endovascular Therapy Following Imaging Evaluation for Acute Ischemic Stroke 3 (DEFUSE 3$)^{42}$ and Clinical Mismatch in the Triage of Wake Up and Late Presenting Strokes Undergoing Neurointervention with Trevo (DAWN) ${ }^{43}$ trial results. Third, intracranial access stability and torqueing forces on the stent retriever may impact the vessel and clot geometry and the respective clot interaction of the device. ${ }^{8}$ Thus, a classification into the true stentretriever failure category may neglect the partial contribution of unstable intracranial access, potentiating difficulties to retrieve the clot or impeding the device efficacy. ${ }^{8}$ Fourth, standardized use of more aggressive rescue approaches for access failures may have averted some reperfusion failures in other centers. Last, distal aspiration techniques with large-bore catheters have gained popularity and have shown increasing effectiveness during the past years. Recent randomized-controlled trial results endorsed them as technically and clinically equally effective approaches (COMPASS/Combined Use of Contact Aspiration and the Stent Retriever Technique Versus Stent Retriever Alone for Recanalisation in Acute Cerebral Infarction [ASTER]). ${ }^{31}$ Although aspiration attempts were implemented in the standard rescue approach at our center, overall distribution of reperfusion failure reasons may differ in centers that more commonly use aspiration techniques (ie, as first attempt) and other categories must be added.

\section{CONCLUSIONS}

Reasons for reperfusion failure in stent-retriever thrombectomy are heterogeneous. The failure to establish intracranial or cervical access is nearly as common as the inability to retrieve the clot despite the clot having been passed and adequate intracranial positioning having been established (true stent-retriever failure). Systematic reporting standards of those reasons may help to elucidate relative frequencies and thereby guide priorities for technical development and scientific effort (eg, adequate subgroup analyses regarding predictive factors). The low rates of delayed recanalization after mechanical reperfusion failures underline the benefit of alternative access routes and the need for a systematic evaluation of other medical (intra-arterial thrombolytics, antiplatelets, and so forth), or, if feasible, mechanical (eg, stent placement) rescue approaches.

Disclosures: Johannes Kaesmacher-RELATED: Grant: Young Talent in Clinical Research Grant (Swiss Academy of Medical Sciences and Bangerter Foundation). Jan Gralla-RELATED: Consulting Fee or Honorarium: Medtronic, Comments: Global Principal Investigator of the SWIFT Direct Trial, consultant for Medtronic, member of the Clinical Event Committee of the PROMISE Study (Penumbra)*; UNRELATED: Grants/Grants Pending: Swiss National Funds, Comments: grant for stroke outcome prediction in MRI,* Marcel Arnold—RELATED: Grant: Swiss Heart Foundation, Comments: research grant*; Consulting Fee or Honorarium: Covidien, Medtronic, Comments: honoraria for lectures; UNRELATED: Consultancy: Bayer HealthCare, BristolMyers Squibb, Boehringer Ingelheim, Daichi Sankyo, Pfizer, Amgen, Comments: Scientific Advisory Board honoraria; Grants/Grants Pending: Swiss National Science Foundation, Comments: research grants. * Urs Fischer-UNRELATED: Consultancy: Medtronic, Stryker*; Grants/Grants Pending: Medtronic, Comments: research grant.* * Money paid to the institution.

\section{REFERENCES}

1. Goyal M, Menon BK, Van Zwam WH, et al; HERMES collaborators. Endovascular thrombectomy after large-vessel ischaemic stroke: a meta-analysis of individual patient data from five randomised trials. Lancet 2016;387:1723-31 CrossRef Medline

2. Manning NW, Chapot R, Meyers PM. Endovascular stroke management: key elements of success. Cerebrovasc Dis 2016;42: 170-77 CrossRef Medline

3. Leslie-Mazwi T, Chandra RV, Fraser JF, et al. AHA/ASA 2018 AIS guidelines: impact and opportunity for endovascular stroke care. JNeurointerv Surg 2018 May 28. [Epub ahead of print] CrossRef Medline

4. Powers WJ, Rabinstein AA, Ackerson T, et al; American Heart Association Stroke Council. 2018 Guidelines for the Early Management of Patients with Acute Ischemic Stroke: A Guideline for Healthcare Professionals from the American Heart Association/American Stroke Association. Stroke 2018;49:e46-110 CrossRef Medline

5. Turk AS, Siddiqui AH, Mocco J. A comparison of direct aspiration versus stent retriever as a first approach ('COMPASS'): protocol. J Neurointerv Surg 2018 Feb 20. [Epub ahead of print] CrossRef Medline

6. Froehler MT, Saver JL, Zaidat OO, et al; on behalf of the STRATIS Investigators. Interhospital transfer prior to thrombectomy is associated with delayed treatment and worse outcome in the STRATIS Registry. Circulation 2017;136:2311-21

7. Zaidat OO, Castonguay AC, Nogueira RG, et al. TREVO stent-retriever mechanical thrombectomy for acute ischemic stroke sec- 
ondary to large vessel occlusion registry. J Neurointerv Surg 2018;10: 516-24 CrossRef Medline

8. Yoo AJ, Andersson T. Thrombectomy in acute ischemic stroke: challenges to procedural success. J Stroke 2017;19:121-30 CrossRef Medline

9. Ribo M, Flores A, Rubiera M, et al. Interhospital transfer prior to thrombectomy is associated with delayed treatment and worse outcome in the STRATIS Registry. J Neurointerv Surg 2013;5(Suppl 1): i70-73 CrossRef Medline

10. Jia B, Feng L, Liebeskind DS, et al. Mechanical thrombectomy and rescue therapy for intracranial large artery occlusion with underlying atherosclerosis. J Neurointerv Surg 2017 Dec 4. [Epub ahead of print] CrossRef Medline

11. Lee JS, Hong JM, Lee KS, et al. Primary stent retrieval for acute intracranial large artery occlusion due to atherosclerotic disease. $J$ Stroke 2016;18:96-101 CrossRef Medline

12. Dobrocky T, Piechowiak E, Cianfoni A, et al. Thrombectomy of calcified emboli in stroke: does histology of thrombi influence the effectiveness of thrombectomy? J Neurointerv Surg 2018;10:345-50 CrossRef Medline

13. Judge C, Mello S, Bradley D, et al. A systematic review of the causes and management of ischaemic stroke caused by nontissue emboli. Stroke Res Treat 2017;2017:7565702 CrossRef Medline

14. Zaidat OO, Yoo AJ, Khatri P, et al; Cerebral Angiographic Revascularization Grading (CARG) Collaborators, STIR Revascularization working group, STIR Thrombolysis in Cerebral Infarction (TICI) Task Force. Recommendations on angiographic revascularization grading standards for acute ischemic stroke: a consensus statement. Stroke 2013;44:2650-63 CrossRef Medline

15. Han HC. Twisted blood vessels: symptoms, etiology and biomechanical mechanisms. J Vasc Res 2012;49:185-97 CrossRef Medline

16. Burzotta F, Nerla R, Pirozzolo G, et al. Clinical and procedural impact of aortic arch anatomic variants in carotid stenting procedures. Catheter Cardiovasc Interv 2015;86:480-89 CrossRef Medline

17. Kaymaz Z, Nikoubashman O, Brockmann M, et al. Influence of carotid tortuosity on internal carotid artery access time in the treatment of acute ischemic stroke. Interv Neuroradiol 2017;23:583-88 CrossRef Medline

18. Yilmaz U, Mühl-Benninghaus R, Simgen A, et al. Carotid elongation does not affect angiographic results of mechanical thrombectomy in acute stroke. Clin Neuroradiol 2016;26:183-87 CrossRef Medline

19. Snelling BM, Sur S, Shah SS, et al. Transradial access: lessons learned from cardiology. J Neurointerv Surg 2018;10:487-92 CrossRef Medline

20. Mokin M, Snyder KV, Levy EI, et al. Direct carotid artery puncture access for endovascular treatment of acute ischemic stroke: technical aspects, advantages, and limitations. J Neurointerv Surg 2015;7: 108-13 CrossRef Medline

21. Blanc R, Piotin M, Mounayer C, et al. Direct cervical arterial access for intracranial endovascular treatment. Neuroradiology 2006;48: 925-29 CrossRef Medline

22. Schwaiger BJ, Gersing AS, Zimmer C, et al. The curved MCA: influence of vessel anatomy on recanalization results of mechanical thrombectomy after acute ischemic stroke. AJNR Am J Neuroradiol 2015;36:971-76 CrossRef Medline

23. Yamamoto S, Yamagami $\mathrm{H}$, Todo $\mathrm{K}$, et al. Correlation of middle cerebral artery tortuosity with successful recanalization using the Merci retrieval system with or without adjunctive treatments. $\mathrm{Neu}$ rol Med Chir (Tokyo) 2014;54:113-19 CrossRef Medline

24. Sporns PB, Hanning U, Schwindt W, et al. Ischemic stroke: histological thrombus composition and pre-interventional CT attenuation are associated with intervention time and rate of secondary embolism. Cerebrovasc Dis 2017:344-50 CrossRef Medline

25. Kaesmacher J, Boeckh-Behrens T, Simon S, et al. Risk of thrombus fragmentation during endovascular stroke treatment. AJNR Am J Neuroradiol 2017;38:991-98 CrossRef Medline

26. Gunning GM, McArdle K, Mirza M, et al. Clot friction variation with fibrin content; implications for resistance to thrombectomy. J Neurointerv Surg 2018;10:34-38 CrossRef Medline
27. Zhu L, Liebeskind DS, Jahan R, et al. Thrombus branching and vessel curvature are important determinants of middle cerebral artery trunk recanalization with Merci thrombectomy devices. Stroke 2012;43:787-92 CrossRef Medline

28. Seker F, Pfaff J, Wolf M, et al. Impact of thrombus length on recanalization and clinical outcome following mechanical thrombectomy in acute ischemic stroke. J Neurointerv Surg 2017;9:937-39 CrossRef Medline

29. Weisstanner C, Gratz PP, Schroth G, et al. Thrombus imaging in acute stroke: correlation of thrombus length on susceptibilityweighted imaging with endovascular reperfusion success. Eur Radiol 2014;24:1735-41 CrossRef Medline

30. Kannath SK, Rajan JE, Sylaja PN, et al. Dwell time of Stentriever influences complete revascularization and first-pass TICI 3 revascularization in acute large vessel occlusive stroke. World Neurosurg 2018;110:169-73 CrossRef Medline

31. Lapergue B, Blanc R, Gory B, et al ASTER Trial Investigators. Effect of endovascular contact aspiration vs stent retriever on revascularization in patients with acute ischemic stroke and large vessel occlusion: the ASTER randomized clinical trial. JAMA 2017;318: 443-52 CrossRef Medline

32. Gory B, Mazighi M, Blanc R, et al; Endovascular Treatment in Ischemic Stroke (ETIS) Research Investigators. Mechanical thrombectomy in basilar artery occlusion: influence of reperfusion on clinical outcome and impact of the first-line strategy (ADAPT vs stent retriever). J Neurosurg 2018 Jan 12:1-10. [Epub ahead of print] CrossRef Medline

33. Consoli A, Rosi A, Coskun O, et al. Thrombectomy for M1-middle cerebral artery occlusion angiographic aspect of the arterial occlusion and recanalization: a preliminary observation. 2018;49: 1286-89 CrossRef Medline

34. Menon BK, Najm M, Al-Ajlan F, et al. Abstract 186: IV tPA recanalization rates by site of occlusion and time after tPA bolus: main results of the Interrsect Multinational Multicenter Prospective Cohort Study. Stroke 2017;48:A186. http://stroke.ahajournals.org/ content/48/Suppl_1/A186.abstract. Accessed January 4, 2018

35. Goh D, Jin S, Jeong HW, et al. Mechanical Solitaire thrombectomy with low-dose booster tirofiban injection. Neurointervention 2016; 11:114-19 CrossRef Medline

36. Zhao W, Che R, Shang S, et al. Low-dose tirofiban improves functional outcome in acute ischemic stroke patients treated with endovascular thrombectomy. Stroke 2017;48:3289-94 CrossRef Medline

37. Brekenfeld C, Schroth G, Mattle HP, et al. Stent placement in acute cerebral artery occlusion: use of a self-expandable intracranial stent for acute stroke treatment. Stroke 2009;40:847-52 CrossRef Medline

38. Baek JH, Kim BM, Kim DJ, et al. Stenting as a rescue treatment after failure of mechanical thrombectomy for anterior circulation large artery occlusion. Stroke 2016;47:2360 -63 CrossRef Medline

39. Crosa R, Spiotta AM, Negrotto M, et al. "Y-stent retriever": a new rescue technique for refractory large-vessel occlusions? J Neurosurg 2018;128:1349-53 CrossRef Medline

40. Chang Y, Kim BM, Bang OY, et al. Rescue stenting for failed mechanical thrombectomy in acute ischemic stroke: a multicenter experience. Stroke 2018;49:958-64 CrossRef Medline

41. Saber H, Narayanan S, Palla M, et al. Mechanical thrombectomy for acute ischemic stroke with occlusion of the M2 segment of the middle cerebral artery: a meta-analysis. J Neurointerv Surg 2018;10: 620-24 CrossRef Medline

42. Albers GW, Marks MP, Kemp S, et al; DEFUSE 3 Investigators. Thrombectomy for stroke at 6 to 16 hours with selection by perfusion imaging. N Engl J Med 2018;378:708-18 CrossRef Medline

43. Nogueira RG, Jadhav AP, Haussen DC, et al; DAWN Trial Investigators. Thrombectomy 6 to 24 hours after stroke with a mismatch between deficit and infarct. N Engl J Med 2018;378:11-21 CrossRef Medline

44. Adams HP, Bendixen BH, Kappelle LJ, et al. Classification of subtype of acute ischemic stroke. Definitions for use in a multicenter clinical trial. TOAST. Trial of Org 10172 in Acute Stroke Treatment. Stroke. 1993;24:35-41 CrossRef 